\title{
A measure of quality of life for clinical trials in chronic lung disease
}

\author{
GORDON H GUYATT, LESLIE B BERMAN, MARIE TOWNSEND, \\ STEWART O PUGSLEY, LARRY W CHAMBERS
}

\begin{abstract}
From the Departments of Medicine and of Clinical Epidemiology and Biostatistics, McMaster University, Hamilton, Ontario
\end{abstract}

ABSTRACT Since the relationships between pulmonary function, exercise capacity, and functional state or quality of life are generally weak, a self report questionnaire has been developed to determine the effect of treatment on quality of life in clinical trials. One hundred patients with chronic airflow limitation were asked how their quality of life was affected by their illness, and how important their symptoms and limitations were. The most frequent and important items were used to construct a questionnaire evaluating four dimensions: dyspnoea, fatigue, emotional function, and the patient's feeling of control over the disease (mastery). Reproducibility, tested by repeated administration to patients in a stable condition, was excellent: the coefficient of variation was less than $12 \%$ for all four dimensions. Responsiveness (sensitivity to change) was tested by administering the questionnaire to 13 patients before and after optimisation of their drug treatment and to another 28 before and after participation in a respiratory rehabilitation programme. In both cases large, statistically significant improvements in all four dimensions were noted. Changes in questionnaire score were correlated with changes in spirometric values, exercise capacity, and patients' and physicians' global ratings. Thus it has been shown that the questionnaire is precise, valid, and responsive. It can therefore serve as a useful disease specific measure of quality of life for clinical trials.

The relationships between changes in symptomatic and functional state in patients with chronic lung disease and changes in conventional physiological indices are often weak. ${ }^{12}$ This is particularly true for interventions such as respiratory rehabilitation programmes, in which patients are taught to cope with their physiological limitations. ${ }^{3-6}$ Direct measurement of the impact on patients' lives is therefore necessary to assess whether interventions are of benefit. Questionnaires that have been developed for this purpose include the oxygen cost diagram $^{7}$ and the baseline and transition dyspnoea indexes. ${ }^{8}$ These tools address patients' dyspnoea but do not focus on the many other aspects of their lives that are affected by the illness. The responsiveness (the ability to detect clinically important change, even if that change is small) of these questionnaires has not

Address for reprint requests: Dr G H Guyatt, Department of Clinical Epidemiology and Biostatistics, 1200 Main Street West, Hamilton, Ontario L8N 3Z5, Canada.

Accepted 12 March 1987 been established, and they have not been directly compared in the clinical trial setting.

We therefore developed a measure of quality of life for patients with chronic airflow limitation designed for use in clinical trials. The questionnaire, the Chronic Respiratory Disease Questionnaire, examines four aspects of patients' lives: dyspnoea, fatigue, emotional function, and mastery (the feeling of control over the disease and its effects). In this paper we describe the development of the questionnaire, and present data regarding its reproducibility, validity (the extent to which it measures what it is intended to measure), and responsiveness.

\section{Methods and results}

PRINCIPLES OF QUESTIONNAIRE DEVELOPMENT The questionnaire was designed to meet the following criteria ${ }^{9}$ :

1 To ensure applicability in assessment of interventions such as multidisciplinary rehabilitation programmes, which seek to modify emotional 
response to illness, the questionnaire should measure not only physical but also emotional function.

2 Items must reflect areas of function that are important to patients with chronic airflow limitation.

3 Summary scores amenable to statistical analysis must be provided.

4 Repetition in stable patients must yield similar results.

5 The questionnaire should be responsive (sensitive to change).

6 The questionnaire should be valid.

7 The questionnaire should be relatively short and simple.

\section{SELECTION OF ITEMS}

A list of items likely to be important to patients with chronic airflow limitation was constructed. The items were generated from a review of published papers, ${ }^{10-20}$ from consultation with respiratory nurse specialists and physicians, and from unstructured interviews with patients. The final "item selection questionnaire" contained 123 items, of which 62 dealt primarily with physical function and 61 with emotional function. Patients were asked to identify items that were problems for them and to rate the importance of each problem item. The item selection questionnaire was administered to 100 patients chosen at random from among those seen in the previous year at a regional respiratory referral centre providing secondary care. Patients were included if their forced expiratory volume in one second $\left(\mathrm{FEV}_{1}\right)$ was consistently less than $70 \%$ of the predicted value.

The results of these interviews are presented in detail in another publication. ${ }^{21}$ In summary, the items chosen most frequently and rated most important by the subjects fell into four categories: shortness of breath, fatigue, emotional function, and mastery or a feeling of control over the disease. The fatigue, emotional function, and mastery dimensions were constructed by choosing the relevant items that gave the highest product of frequency and importance in the item selection questionnaire.

Since items associated with dyspnoea varied widely, depending on the patient's sex, range of activities and level of disability, questions on dyspnoea were developed on an individual basis. Patients are asked to list activities associated with shortness of breath that they perform frequently and are important in their day to day lives. Twenty six activities are offered as suggestions to aid recall. Patients are then asked to choose the five most important activities from among those they have listed. These items constitute the dyspnoea dimension for that patient for the duration of the study.

The Chronic Respiratory Disease Questionnaire that emerged from this process contained 20 items, $\stackrel{\vec{O}}{\rightarrow}$ which were serially pretested to clarify issues of wording and presentation of items. Initial $\frac{\bar{\sigma}}{\bar{\omega}}$ administration of the questionnaire takes a maximum $\frac{\mathrm{m}}{\widehat{D}}$ of 30 minutes, and usually 15-25 minutes. Follow up $\stackrel{\varnothing}{2}$ administration takes a maximum of 20 minutes, and $\%$ usually 10-15 minutes. The structure and content of $\vec{\circ}$ the questionnaire are described in the appendix. Studies were then undertaken to clarify the $\vec{\omega}$ reproducibility, responsiveness, and validity of the questionnaire.

\section{REPRODUCIBILITY}

A single interviewer administered the questionnaire to 25 patients with stable chronic airflow limitation (best $\omega$ $\mathrm{FEV}_{1}$ less than $70 \%$ of predicted, $\mathrm{FEV}_{1} / \mathrm{VC}$ less than $ᄋ$ $0.7)$ six times at two week intervals. Mean scores were similar for all four dimensions at each administration; $O$ there were no clinically important or statistically significant trends toward either improvement or ${ }_{\mathbb{D}}$ deterioration. The coefficient of variation (the within person standard deviation divided by the mean) was $\vec{\oplus}$ $6 \%$ for the dyspnoea dimension, $9 \%$ for both fatigue. and emotional function, and $12 \%$ for mastery. These results compare favourably with most indices of functional state and respiratory function. ${ }^{22}$

\section{RESPONSIVENESS}

The questionnaire was administered to 13 patients with chronic lung disease whose respiratory physi- $\frac{0}{3}$ cians predicted improvement with institution or modification of treatment. The underlying conditions included chronic airflow limitation (11 patients) and pulmonary fibrosis (two patients). Treatments included bronchodilators and steroids. The questionnaire was administered at the time of consultation and $\frac{\sigma}{\sigma}$ at a follow up visit two to six weeks later. Despite only small improvements in spirometric values, scores on $\delta$ each of the four questionnaire dimensions were sub- $\bar{z}$ stantially better at follow up. The scores of all four 을 dimensions, standardised on a 10 point scale (so that, for example, the score on the dyspnoea dimension, which has a maximum of 35 , was divided by $3 \cdot 5$ ), are depicted in figure 1.

In the second responsiveness study we administered $\mathcal{O}$ our questionnaire, along with several other question- N naires (see below), to 28 patients with chronic airflow 0 limitation entering our multidisciplinary inpatient respiratory rehabilitation programme. The question- $\overparen{\mathbb{D}}$ naire was repeated two weeks after discharge. Sub- $\stackrel{\infty}{+}$ stantial improvement in scores occurred on all four 0 dimensions (fig 2).

COMPARISON WITH EXISTING MEASURES

A paired $t$ test of the differences in score between $\frac{Q}{\sigma}$ admission to the rehabilitation programme and two 


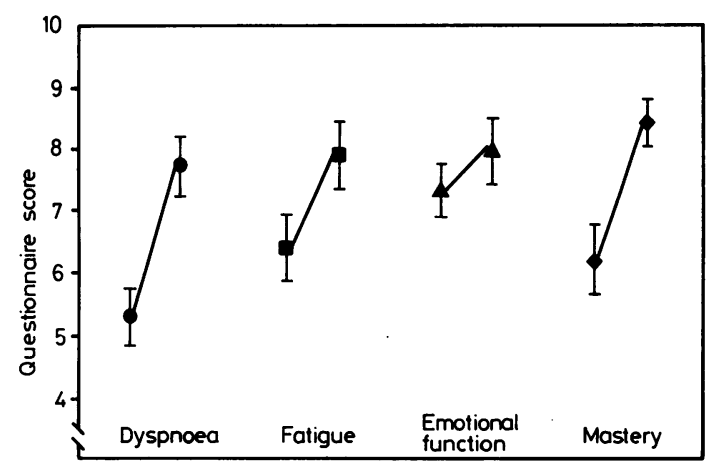

Fig 1 Chronic Respiratory Disease Questionnaire dimension changes: mean (SEM) values before and after pharmacological intervention.

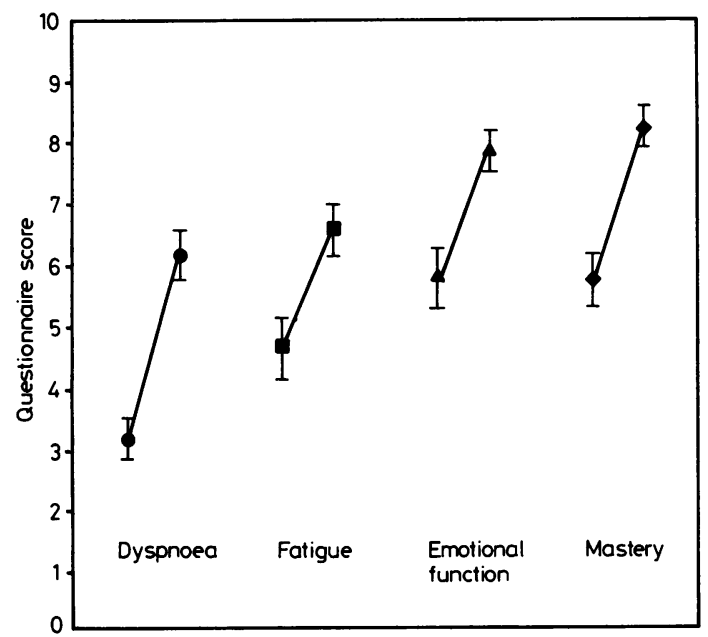

Fig 2 Chronic Respiratory Disease Questionnaire dimension changes: mean (SEM) values before and after respiratory rehabilitation.

weeks after discharge was conducted for the four questionnaire dimensions, the oxygen cost diagram, the Transition Dyspnoea Index, the Rand dyspnoea questionnaire (a modified version of the British Medical Research Council dyspnoea questionnaire constructed by investigators at the Rand Corporation), ${ }^{23}$ and the Rand physical and emotional function questionnaires (constructed as quality of life measures for the general population). ${ }^{16}$ To examine the responsiveness of the various questionnaires we compared the $t$ values relating to the differences in score between baseline (before rehabilitation) and follow up (after rehabilitation) for each questionnaire. The $t$ value for each of the four Chronic Respiratory Disease Questionnaire dimensions was similar to that of the Transition Dyspnoea Index and greater than that of any of the other measures, thus showing the superior responsiveness of our questionnaire (table 1).

\section{VALIDITY}

Evidence for the validity of the Chronic Respiratory Disease Questionnaire can be gleaned from the data already presented: questionnaire scores remain stable in patients deemed clinically stable, and improve in groups in which clinical improvement is anticipated. To study the validity of the questionnaire further several other tests were administered to patients before and after the rehabilitation programme, and then serially during six months. The tests included FEV slow vital capacity (SVC), a six minute walk, the oxygen cost diagram, and global ratings of dyspnoea, fatigue, and emotional function from patients, patients' relatives, a physician, and a physiotherapist.

Using an established technique to arrive at consensus, ${ }^{24}$ we generated a priori predictions about how closely changes in each of these measurements should correlate with changes in our four questionnaire dimensions if the questionnaire is really measuring disease specific quality of life. Agreement between predicted and observed correlations was good (weighted kappa 0.51, p < 0.05). In general, we found moderate correlations between changes in the questionnaire responses and changes in related measurements (such as the questionnaire's dyspnoea dimension and the six minute walk test); correlations between less closely related variables (such as the questionnaire's emotional function dimension and the walk test) were lower. Examples of the correlations are presented in table 2 .

\section{Discussion}

The Chronic Respiratory Disease Questionnaire has several advantages over existing measurements of

Table 1 Questionnaire responsiveness: the Chronic Respiratory Disease Questionnaire (CRQ) versus other measurements

\begin{tabular}{|c|c|c|c|c|c|}
\hline$C R Q$ dimension & $t$ & $p$ & Questionnaire & $t$ & $p$ \\
\hline $\begin{array}{l}\text { Dyspnoea } \\
\text { Emotional function } \\
\text { Fatigue } \\
\text { Mastery }\end{array}$ & $\begin{array}{l}5 \cdot 97 \\
4 \cdot 97 \\
4 \cdot 83 \\
6 \cdot 44\end{array}$ & $\begin{array}{l}<0.001 \\
<0.001 \\
<0.001 \\
<0.001\end{array}$ & $\begin{array}{l}\text { Transition Dyspnoea Index } \\
\text { Oxygen cost diagram } \\
\text { Rand dyspnoea index } \\
\text { Rand quality of life } \\
\text { Physical } \\
\text { Emotional }\end{array}$ & $\begin{array}{l}6.36 \\
1.05 \\
1.12 \\
1.68 \\
1.98\end{array}$ & $\begin{array}{c}<0.001 \\
0.31 \\
0.28 \\
0.12 \\
0.06\end{array}$ \\
\hline
\end{tabular}


Table 2 Correlations between Chronic Respiratory Disease Questionnaire (CRQ) dimensions and other measurements $\dagger$

\begin{tabular}{|c|c|c|c|}
\hline & $\begin{array}{l}C R Q \\
\text { dyspnoea }\end{array}$ & $\begin{array}{l}C R Q \\
\text { fatigue }\end{array}$ & $\begin{array}{l}C R Q \\
\text { Emotional } \\
\text { function }\end{array}$ \\
\hline $\begin{array}{l}\text { Walk test } \\
\text { Patient global rating } \\
\text { dyspnoea }\end{array}$ & $\begin{array}{l}0 \cdot 46^{*} \\
0 \cdot 37^{\star}\end{array}$ & $\begin{array}{l}0 \cdot 35^{\star} \\
0 \cdot 62^{\star}\end{array}$ & $\begin{array}{l}0.19 \\
0.37^{*}\end{array}$ \\
\hline $\begin{array}{l}\text { Patient global rating } \\
\text { fatigue }\end{array}$ & $0 \cdot 36^{\star}$ & $0.42^{\star}$ & 0.27 \\
\hline $\begin{array}{l}\text { Patient global rating } \\
\text { emotional function }\end{array}$ & $0.35^{*}$ & $0 \cdot 36^{\star}$ & $0 \cdot 35^{\star}$ \\
\hline
\end{tabular}

functional state. Items were generated from statements about disease related problems of daily living made by 100 patients with chronic airflow limitation, randomly selected from those attending a chest clinic. This selection process ensures that questionnaire items concentrate on areas of dysfunction most important to patients with chronic airflow limitation. The questionnaire is administered directly to the patients. While existing disease specific measures focus on shortness of breath, our questionnaire includes other major aspects of dysfunction as well. The reproducibility of the questionnaire remains excellent over 12 weeks. The questionnaire proved as responsive as or more responsive than the two existing questionnaires with which it was compared. The highly significant differences detected in relatively small numbers of subjects suggest that this questionnaire is sufficiently responsive to detect differences in quality of life with sample sizes that can be achieved in single centre studies.

We cannot say how much of the improvement observed in either the clinic or the rehabilitation populations was due to a specific effect of the intervention, and how much was a placebo effect. Since placebos do make people feel better, and the questionnaire measures how people feel, we would anticipate that the questionnaire would be responsive to placebo effects. Responsiveness to placebo effects also characterises other measurements of outcome used in clinical trials in chronic airflow limitation, including spirometry, walking tests, and laboratory exercise tests. The extent to which the questionnaire is able to detect specific treatment effects in a randomised control trial remains to be determined.

The results reported here require confirmation in the hands of other investigators. Nevertheless, we believe that the evidence we have presented suggests that the questionnaire is ready for use in clinical trials. The Chronic Respiratory Disease Questionnaire and other disease specific questionnaires take only a few minutes to administer. We therefore recommend that in- $\overrightarrow{\vec{s}}$ vestigators interested in determining the effects of $\frac{7}{0}$ their interventions on quality of life in patients with $\frac{\bar{\sigma}}{\square}$ chronic airflow limitation should administer several $\bar{\omega}$ disease specific questionnaires (and if possible a ques- $\widehat{\Phi}$ tionnaire designed for the general population as well) to study participants.

The full questionnaire, as well as a training manual $\vec{\circ}$ and training tape for administration of the question- $\overrightarrow{\vec{H}}$ naire, are available from the first author.

We would like to thank the following individuals for their help in the collection and collation of the data $\stackrel{\vec{N}}{ }$ and the preparation of the manuscript: Penelope $\vec{O}$ Thompson, Barbara Sackett, Jana Kendry, Denise $\searrow$ Short, Debbie Maddock, Christine Meiklejohn, and $\omega$

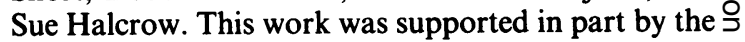
Ontario Ministry of Health and St Joseph's Hospital Foundation, Hamilton, Ontario. GHG is a career scientist of the Ontario Ministry of Health.

\section{Appendix: Summary of the Chronic Respiratory Disease Questionnaire}

The questionnaire begins by eliciting five activities in which the patient experiences dyspnoea during day to day activities:

1 I would like you to think of the activities that you have done during the last 2 weeks that have made you feel short of breath. These should be activities which you do frequently and which are important in your day to day life. Please list as many activities as you can that you음 have done during the last 2 weeks that have made you feel short of breath.

C Circle the number on the answer sheet list adjacent to each activity mentioned. If an activity mentioned is not on the list, write it in, in the respondent's own words, in the space pro-음 vided.]

Can you think of any other activities you have done duringo the last 2 weeks that have made you feel short of breath? [Record additional items]

2 I will now read a list of activities which make some people with lung problems feel short of breath. I will pause after each item long enough for you to tell me if you have felt short of breath doing that activity during. the last 2 weeks. If you haven't done the activity during the last 2 weeks, just answer "No." The activities are:" [ Read items, omitting those which respondent has volunteered spontaneously. Pause after each item to give respondent d chance to indicate whether he/she has been short of breatho while performing that activity during the last week. Circle the number adjacent to appropriate items on answer sheet.]

1 Being angry or upset

2 Having a bath or shower

3 Bending

4 Carrying, such as carrying groceries

5 Dressing

6 Eating

7 Going for a walk

8 Doing your housework 
9 Hurrying

10 Lying flat

11 Making a bed

12 Mopping or scrubbing the floor

13 Moving furniture

14 Playing with children or grandchildren

15 Playing sports

16 Reaching over your head

17 Running, such as for a bus

18 Shopping

19 Talking

20 Vacuuming

21 Walking around your own home

22 Walking uphill

23 Walking upstairs

24 Walking with others on level ground

25 Preparing meals

26 While trying to sleep

If more than five items have been listed the interviewer then helps the subject determine the five activities which are most important in the subject's day to day life.

3 (a) Of the items which you have listed, which is the most important to you in your day to day life? I will read through the items, and when I am finished I would like you to tell me which is the most important.

[Read through all items spontaneously volunteered and those from the list which patient mentioned.]

Which of these items is most important to you in your day to day life?

[List item on response sheet.]

This process is continued until the five most important activities are determined. The interviewer then proceeds to find out how much shortness of breath the subject has experienced during the prior two weeks. Throughout the questionnaire, response options are printed on different colour cards with which the subject is presented.

4 I would now like you to describe how much shortness of breath you have experienced during the last 2 weeks while doing the five most important activities you have selected.

(a) Please indicate how much shortness of breath you have had during the last 2 weeks while [Interviewer: Insert activity list in $3 a$ ] by choosing one of the following options from the card in front of you [green card]:

1 Extremely short of breath

2 Very short of breath

3 Quite a bit short of breath

4 Moderate shortness of breath

5 Some shortness of breath

6 A little shortness of breath

7 Not at all short of breath

This process continues until the subject's degree of dyspnoea on all five of his or her most important activities has been determined. The remainder of the questionnaire asks 15 standard questions, which are identical for each subject. The wording is deliberately repetitious, experience having taught us that the repetition ensures subjects' understanding. Re- sponse options are consistently presented as seven point scales. An example of the way the questions are structured follows.

5 In general, how much of the time during the last 2 weeks have you felt frustrated or impatient? Please indicate how often during the last 2 weeks you have felt frustrated or impatient by choosing one of the following options from the card in front of you [blue card]:

1 All of the time

2 Most of the time

3 A good bit of the time

4 Some of the time

5 A little of the time

6 Hardly any of the time

7 None of the time

The wording structure of the other questions is identical, and appropriate seven points scales are offered for each question. The content of the remaining 14 questions is as follows:

6 How often during the past 2 weeks did you have a feeling of fear or panic when you had difficulty getting your breath?

7 What about fatigue? How tired have you felt over the last 2 weeks?

8 How often during the last 2 weeks have you felt embarrassed by your coughing or heavy breathing?

9 In the last 2 weeks, how much of the time did you feel very confident and sure that you could deal with your illness?

10 How much energy have you had in the last 2 weeks?

11 In general, how much of the time did you feel upset, worried, or depressed during the last 2 weeks?

12 How often during the last 2 weeks did you feel you had complete control of your breathing problems with shortness of breath and tiredness?

13 How much of the time during the last 2 weeks did you feel relaxed and free of tension?

14 How often during the last 2 weeks have you felt low in energy?

15 In general, how often during the last 2 weeks have you felt discouraged or down in the dumps?

16 How often during the last 2 weeks have you felt worn out or sluggish?

17 How happy, satisfied, or pleased have you been with your personal life during the last 2 weeks?

18 How often during the last 2 weeks did you feel upset or scared when you had difficulty getting your breath?

19 In general, how often during the last 2 weeks have you felt, restless, tense, or uptight? 


\section{References}

1 Alexander MR, Dull WL, Kasik JE. Treatment of chronic obstructive pulmonary disease with orally administered theophylline. A double-blind controlled study. JAMA 1980;244:2286-90.

2 Eaton ML, MacDonald FM, Church TR, Niewoehner DE. Effects theophylline on breathlessness and exercise tolerance in patients with chronic airflow obstruction. Chest 1982;82:538-42.

3 Haas A, Cardon H. Rehabilitation in chronic obstructive pulmonary disease. Med Clin N Am 1969;53:593-606.

4 Petty TL, Brink GA, Miller MW, Corsello PR. Objective functional improvement in chronic airway obstruction. Chest 1970;57:216-23.

5 Kimbel P, Kaplan AS, Alkalay I, Lester D. An inhospital program for rehabilitation of patients with chronic obstructive pulmonary disease. Chest 1971;60 (suppl): 6-10.

6 Agle DP, Baum GL, Chester EH, Wendt M. Multidiscipline treatment of chronic pulmonary insufficiency. 1-Psychologic aspects of rehabilitation. Psychosom Med 1973;35:41-9.

7 McGavin CR, Artvinli M, Naol H. Dyspnea, disability and distance walked: comparison of estimates of exercise performance in respiratory disease. $\mathrm{Br} \mathrm{Med} \mathrm{J}$ 1978;ii:241-3.

8 Mahler DA, Weinberg DH, Wells CK, Feinstein AR. The measurement of dyspnea. Contents, interobserver agreement, and physiologic correlates of two new clinical indexes. Chest 1984;85:751-8.

9 Kirshner B, Guyatt G. A methodological framework for assessing health indices. J Chron Dis 1985;38:27-36.

10 Fishman DB, Petty TL. Physical, symptomatic and psychological improvement in patients receiving comprehensive care for chronic airway obstruction. J Chron Dis 1971;24:775-85.

11 Moser KM, Bokinsky GE, Savage RT, Archibald CJ, Hansen PR. Results of a comprehensive rehabilitation program. Physiologic and functional effects on patients with chronic obstructive pulmonary disease. Arch Intern Med 1980;140:1596-601.

12 Dudley DL, Glaser EM, Jorgenson BN, Logan DL. Psychosocial concomitants to rehabilitation in chronic obstructive pulmonary disease. Part 2. Psychosocial treatment. Chest 1980;77:544-51.

13 Dudley DL, Glaser EM, Jorgenson. BN, Logan DL. Psy믐 chosocial concomitants to rehabilitation in chronioक obstructive pulmonary disease. 3-Dealing with psychiatric disease (as distinguished from psychosocia or psychophysiologic problems). Chest 1980, 77:677-84.

14 Kinsman RA, Yaroush RA, Fernandez E, Dirks JF Schocket M, Fukuhara J. Symptoms and experiences in chronic bronchitis and emphysema. Ches? 1983;83:755-61.

15 McSweeny AJ, Grant I, Heaton RK, Adams KM Timms RM. Life quality of patients with chronic obstructive pulmonary disease. Arch Intern Med5 1982;142:473-8.

16 Ware JE, Brook RH, Davies-Avery A, et al. Conceptualization and measurement of health for adults in the health insurance study. Vol 1, Model of health and methodology. Santa Monica, California: Rando Corporation, 1980.

17 Kaplan RM, Bush JW, Berry CC. Health status: types of validity and the index of well-being. Health Services Research 1976;11:478-507.

18 Bergner M, Bobbit RA, Carter WB, Gilson BS. Theळ sickness impact profile: Development and finar revision of a health status measure. Med Care 1981;19:787-805.

19 Parkerson GR, Gehlback SH, Wagner EH, et al. The Duke-UNC Health Profile. Med Care 1981;19:806-28.

20 Hunt SM, McKenna SP, McEwen J, et al. A quantitativeo approach to perceive health status: $A$ validation of study. J Epidemiol Commun Health 1980;34:281-6.

21 Guyatt GH, Townsend M, Berman LB, Pugsley SO. Quality of life in patients with chronic airflow limitation. Br J Dis Chest 1987;81:45-54.

22 Guyatt GH, Thompson PJ, Berman LB, et al. How should we measure function in patients with chronico heart and lung disease? J Chron Dis 1985;38:517-24. ָे

23 Rosenthal M, Lohr KN, Rubenstein RS, Goldberg GA, Brook RH. Conceptualization and measurement of physiologic health for adults: congestive heart failure. Santa Monica, California: Rand Corporation, 1981.

24 Fink A, Kosecoff J, Chassin M, Brook RH. Consensus methods: Characteristics and guidelines for use. $A m$ J Publ Health 1984;74:979-83. 